\title{
PENGARUH KONSUMSI RUMAH TANGGA, PERUBAHAN IKLIM, MONOPOLI HARGA, LUAS LAHAN, DAN MODAL USAHA TERHADAP PENDAPATAN PETANI KAKAO DI NAGARI KUBANG KECAMATAN LIMA PULUH KOTA
}

\author{
Shinta Andini Putri, Ansofino, Putri Meliza Sari \\ Program Studi Pendidikan Ekonomi STKIP PGRI Sumatera Barat \\ Shintaandiniputrii@gmail.com
}

\begin{abstract}
This study aims to analyze 1) Effect of Rt Consumption on the income of cocoa farmers, 2) Effect of Climate Change on cocoa farmers 'income, 3) Effect of Price Monopoly on cocoa farmers' income, 4) Effect of Land Area on the incomT of cocoa farmers, 5) Effect of Capital on Cocoa farmers' income, 6) The influence of household consumption, climate change, price monopoly, land area, and capital together on the income of cocoa farmers. When this research was conducted in December 2019. This type of research is descriptive and associative. The population in this study were cocoa farmers living in Nagari Kubang, Guguak District, Lima Puluh Kota District. he results showed that: (1) Rt consumption affected the income of cocoa farmers $t$ counted 4.011084> table 1.663. (2) Climate change affects the income of cocoa farmers $t$ count 2.184027> t table 1.663. (3) Price monopoly affects the income of cocoa farmers, $t$ count is 1.681352> table 1.663. (4) Land area has no effect on the income of cocoa farmers t count of $0.844364<\mathrm{t}$ table 1.663. (5) Capital influences the income of cocoa farmers $\mathrm{t}$ arithmetic as big as 14.15188> table 1.663. (6) Household consumption, climate change, price monopoly, land area, and capital together have a significant influence on the income of cocoa farmers, the calculated $\mathrm{F}$ value is $175.5961>\mathrm{F}$ tables 2.32 and 7.213212> F table 2.32 and value significant $0.00000<0.05$ and $0.000040<0.05$.
\end{abstract}

Keywords: Farmer Income, Household Consumption, Climate Change, Price Monopoly, Land Area, Capital

\section{PENDAHULUAN}

Pembangunan Sektor pertanian merupakan sektor strategis bagi perekonomian Kabupaten Lima Puluh Kota, ini terlihat dari kontribusi sektor pertanian pada PDRB dari tahun ke tahun memperlihatkan peningkatan.
Dalam meningkatkan hasil pertanian selain dari usaha yang dilakukan pada sistem pengolahan yang dilakukan oleh pemilik lahan, keadaan iklim juga dapat mempengaruhi jumlah peningkatan produksi perkebunan masyarakat. yang siudah diutarakan dimuka 
bumi. keterkaitan antara komoditi ekologi dengan kecocokan dan keamanan jenis tanaman yang dilakukan oleh rumah tangga petani serta kaitannya dengan pendapatan rumah tangga petani sebagai dampak dari terjadinya perubahan iklim.

Curah hujan yang dibutuhkan yaitu sekitar $1.500 \mathrm{~mm} \mathrm{sd} 2.500 \mathrm{~mm}$ per tahun. Luas lahan adalah area yang akan ditanam bibit oleh petani, luas kebun ini merupakan faktor penentu oleh seorang petani dalam memperoleh hasil produksi.

Dalam usaha pertanian dibidang perkebunan yang menjadi lahan produksinya adalah kebun kakao. Penggunaan pertanian selalun didasarkan atau dikembangkan pada luas lahan pertanian.

Seperti yang dialami petani kakao di Kabupaten Lima Puluh Kota modal yang dimiliki pelaku masih tergolong rendah. Namun pada kenyataanya sekarang banyak para petani kakao yang bermasalah dengan modal yang dimilikinya, sehingga juga berdampak terhadap pendapat yangdiperolehnya.

Berdasarkan inilah maka penulis tertarik untuk meneliti bagaimana "Pengaruh konsumsi rumah tangga, Perubahan Iklim, Monopoli Harga , Luas Lahan Dan Modal usaha Terhadap Pendapatan Petani Kakao Di Nagari Kubang Kecamatan Guguak Kabupaten Lima Puluh Kota".

\section{METODE PENELITIAN}

Jenis penelitian ini adalah deskriptif dan korelasional, penelitian ini dilakukan di Nagari Kubang Kabupaten Lima Puluh Kota Provinsi Sumatera Barat bulan September tahun 2019 yang ada di Nagari Kubang karena memiliki luas lahan kakao terluas diantara nagarinagari yang lain dan mayoritas masyarakat masih bertani kakao dengan jumlah petani sebanyak 190 KK dengan teknik pengambilan Stratified Random Sampling sehingga diperoleh sampel petani lahan sempit sebanyak 55 orang dan petani dengan lahan luas sebanyak 32 orang.

$$
\text { Variabel bebas dalam }
$$
penelitian ini adalah konsumsi Rumah Tangga, Perubahan iklim, Monopoli Harga, Luas lahan, dan Modal usaha dan variabel terikat atau variabel dependen adalah pendapatan 
petani kakao. Uji yang digunakan

adalahregresi linear berganda.

Analisis Regresi Linier Berganda
Pembentukan model regresi linier berganda bertujuan untuk mengetahui arah pengaruh

Tabel 1. Hasil Pengujian Persamaan Regresi

Dependent Variable: Y

Method: Least Squares

Date: 02/24/20 Time: 13:01

Sample: 190

Included observations: 90

\begin{tabular}{lrlrl}
\hline \hline \multicolumn{1}{c}{ Variable } & Coefficient & Std. Error & t-Statistic & Prob. \\
\hline \hline C & -1411482. & 941153.7 & -1.499736 & 0.1373 \\
X2 & 183757.9 & 71652.36 & 2.564575 & 0.0121 \\
X4 & -654.2816 & 156.5605 & -4.179096 & 0.0001 \\
X5 & 0.194981 & 0.006042 & 32.26846 & 0.0000 \\
\hline \hline R-squared & 0.930625 & Mean dependent var & 1821878. \\
Adjusted R-squared & 0.928205 & S.D. dependent var & 3169873. \\
S.E. of regression & 849355.9 & Akaike info criterion & 30.18577 \\
Sum squared resid & $6.20 \mathrm{E}+13$ & Schwarz criterion & 30.29687 \\
Log likelihood & -1354.360 & Hannan-Quinn criter. & 30.23057 \\
F-statistic & 384.5453 & Durbin-Watson stat & 1.792765 \\
Prob(F-statistic) & 0.000000 & & \\
\hline \hline
\end{tabular}

Sumber: Olahan Data Primer Tahun 2019

Model persamaan regresi

linear berganda yang dapat

dituliskan dari hasil tersebut adalah

sebagai berikut:

$$
\begin{array}{llr}
\mathrm{Y} & =\mathrm{a}+\mathrm{b} 2 \mathrm{X} 2+\mathrm{b}_{4} \mathrm{X}_{4}+\mathrm{b}_{5} \mathrm{X}_{5}+\mathrm{e} \\
\mathrm{Y} & =-141182+183757,9 \quad \mathrm{X}_{2}-
\end{array}
$$$$
654,2816 \mathrm{X}_{4}+0,194981 \mathrm{X}_{5}
$$

Dari model persamaan regresi

linier berganda di atas dapat diketahui bahwa:

1) Nilai konstanta sebesar 141182 berarti tanpa adanya dampak sebesar 141182 Hal ini berarti bahwa apabila variabel bebas nilainya konstan (konsumsi
Rumah Tangga, perubahan iklim, monopoli harga, luas lahan dan modal) maka nilai variabel pendapatan sebesar Rp.141182.

2) Koefisien regresi perubahan iklim $\left(\mathrm{X}_{2}\right)$ sebesar 183757,9 yang bertanda positif. Hal ini berarti adanya dampak positif perubahan iklim terhadap pendapatan petani. Artinya apabila nilai Rp.183757,9

3) Koefisien regresi variabel luas lahan $\left(\mathrm{X}_{4}\right)$ sebesar 654,2816 yang bertanda negatif. Artinya apabila nilai variabel luas lahan 
meningkat sebesar satu satuan maka akan menurunkan pendapatan petani Rp.654,2816. Dengan asumsi variabel lain tidak mengalami perubahan atau konstan.

4) Koefisien regresi variabel modal $\left(\mathrm{X}_{5}\right)$ sebesar 0,194981 yang bertanda positif. Hal ini berarti adanya dampak positif modal terhadap pendapatan petani. Artinya apabila nilai variabel modal meningkat sebesar satu satuan maka akan meningkatkan pendapatan petani sebesar Rp.0,194981. tidak mengalami perubahan atau konstan.

Hasil Pengujian Hipotesis Berstrata Sampel Penelitian Kategori Luas Lahan Sempit Dan Luas Lahan Luas.

Pengujian ini dilaksanakan untuk meninjau seberapa besar dampak variabel konsumsi Rumah Tangga, perubahan iklim,monopoli harga, luas lahan, modal. terhadap pendapatan petani kakao berdasarkan luas lahan sempit dan luas lahan luas.

Tabel 2: Hasil Regresi Faktor Yang Mempengaruhi Pendapatan Berdasarkan Kategori Luas Lahan

\begin{tabular}{lrrrrrr}
\hline \multicolumn{1}{c}{ Variabel } & \multicolumn{3}{c}{ Luas Lahan Luas } & \multicolumn{3}{c}{ Luas Lahan Sempit } \\
& $\mathrm{B}$ & $\mathrm{T}$ & $\mathrm{Sig}$ & $\mathrm{B}$ & $\mathrm{T}$ & $\mathrm{Si}$ \\
& & & & & & $\mathrm{g}$ \\
\hline Konsumsi & 2.32226 & 1.860579 & 0.072 & 3.272436 & 3.961799 & 0.0002 \\
Perubahan Iklim & 292230. & 1.517413 & 0.139 & 153741.3 & 2.204818 & 0.0321 \\
(x2) & 2 & & 6 & & & \\
$\begin{array}{l}\text { Monopoli Harga } \\
\text { (x3) }\end{array}$ & 519.059 & 1.773693 & 0.086 & 51.25697 & 0.339344 & 0.7358 \\
Modal (x5) & 7 & & 3 & & & \\
& 0.19964 & 19.17632 & 0.000 & 0.044995 & 1.012237 & 0.3163 \\
\hline
\end{tabular}

Sumber: Olah data Primer Tahun 2019

Pada tabel diatas diperoleh hasil variabel konsumsi Rumah Tangga sangat berpengaruh pada Pendapatan terutama luas lahan sempit, karena koefisiennya adalah 3,272436 dengan thitung 3,961799. Luas lahan sempit akan meningkat dibandingkan luas lahan luas. Pada sisi Konsumsi Rumah Tanggga luas lahan sempit sangat sensitif dibandingkan luas lahan luas.

Variabel perubahan iklim sangat berpengaruh pada pendapatan terutama luas lahan sempit karena koefisiennya adalah 153741,3 dengan thitung 2,204818. Luas lahan sempit akan meningkat 
dibandingkan luas lahan luas. Pada perubahan Iklim, luas lahan sempit sangat sensitif dibandingkan luas lahan luas.

Variabel monopoli harga sangat berpengaruh pada Pendapatan terutama luas lahan luas karena koefisiennya adalah 519,0597 dengan thitung 1.773693. Luas lahan luas akan meningkat dibandingkan luas lahan kecil. Pada sisi Monopoli Harga, luas lahan luas sangat sensitif dibandingkan luas lahan sempit.

Variabel modal sangat berpengaruh pada pendapatan terutama luas lahan luas karena koefisiennya adalah 0,199645 dengan thitung 19,17632 Luas lahan luas akan meningkat dibandingkan luas lahan sempit. Pada sisimodal luas lahan luas sangat sensitif dibandingkan luas lahan sempit.

Pembahasan

1. Pengaruh Konsumsi Rumah Tangga Terhadap Pendapatan Petani Kakao.

Hasil penelitian ditemukan terdapat pengaruh negatif konsumsi Rumah Tangga terhadap hasil pendapatan petani kakao. Koefisien regresi konsumsi Rumah Tangga terhadappendapatan petani kakao, dimana nilai t hitung 1,427889 dan nilai $(\mathrm{sig}=0,1570>0,05)$. Dengan $\mathrm{df}=90-6=84$ diperoleh $\mathrm{t}_{\text {tabel }}$ sebesar 1,663, dari hasil di atas dapat dilihat bahwa $t_{\text {hitung }}<t_{\text {tabel }}$ atau $1,427889<1,663$, maka konsumsi Rumah Tanggatidak berpengaruh terhadap pendapatan petani kakao.

Konsumsi Rumah Tangga adalah dimana untuk memproduksi barang guna memenuhi ayam, minyak tanah, daging ayam, susu, garam, jagung. Teori keynes menyatakan bahwa banyak tingkat konsumsinya, dan nya akan nol.

2. Pengaruh Perubahan Iklim Terhadap Pendapatan Petani kakao

Hasil penelitian ditemukan terdapat pengaruh positif variabel perubahan iklim terhadap pendapatan petani kakao. Koefisien regresi perubahan iklim terhadap pendapatan petani kakao, dimana nilai $t$ hitung 2,106210 dan nilai $(\operatorname{sig}=0,0382<$ 0,05). Menurut (Yukesma, 2017)) iklim berpengaruh terhadap pendapatan petani, semakin bagus keadaan iklim maka akan meningkatkan pendapatan petani. Sedangkan menurut (Selvia, 2017) perubahan iklim sangat berpengaruh terhadap pendapatan petani iklim 
merupakan gambaran jumlah hari hujan sehingga menentukan hasil yang akan diperoleh oleh petani. Apabila jumlah hari hujan banyak maka tanaman kakao akan membusuk sedangkan apabila jumlah hari hujan sedikit maka tanaman kakao tidak akan subur dan timbul bintik-bintik hitam pada buah karena kakao merupakan tanaman yang cocok dengan curah hujan yang sedang. bahwa perubahan iklim berpengaruh terhadap pendapatan petani kakao.

\section{Pengaruh Monopoli Harga terhadap Pendapatan Petani Kakao. \\ Hasil penelitian ditemukan} terdapat pengaruh negatif variabel monopoli harga terhadap pendapatan petani kakao. Koefisien regresi monopoli harga terhadappendapatan petani kakao, dimana nilai $\mathrm{t}$ hitung 0,456736 dan nilai $(\operatorname{sig}=0,6490>$ 0,05). Dengan df $=90-6=84$

Menurut (Mawardati, 2015) harga berpengaruh sangat signifikan terhadap pendapatan petani, yaitu jika harga rendah maka pendapatan akan menurun dan jika harga tinggi maka pendapatn akan meningkat Artinya semakin rendah harga jual semakin sedikit pendapatan yang diperoleh oleh petani, begitu juga sebaliknya jika harga jual tinggi maka pendapatan petani juga akan meningkat.

4. Pengaruh Luas Lahan Terhadap Pendapatan Petani Kakao

Hasil penelitian ditemukan terdapat pengaruh negatif variabel. Koefisien regresi luas lahan terhadap pendapatan petani kakao, dimana nilai thitung 4,387868 dan nilai (sig $=0,0000<0,05)$. Dengan $\mathrm{df}=90-6$ $=84$ diperoleh $t_{\text {tabel }}$ sebesar 1,663, dari hasil di atas dapat dilihat bahwa $t_{\text {hitung }}<\mathrm{t}_{\text {tabel }}$ atau 4,387868>1,662, maka luas lahan berpengaruh terhadap pendapatan petani kakao.

Menurut (Soekartawi, 2002). Pertanian mempunyai kedudukan paling penting dalam faktor pertanian, karena jika tidak ada lahan pertanian maka proses pertanian tidak akan terjadi. Menurut (Daniel, 2004) sebagai faktor utama dalam sektor pertanian untuk tetap mempertahankan kesuburan tanah petani juga harus memperhatikan keadaan fisik tanah dan kekayaan kimia yang tergantung didalamnya.
5. Pengaruh Modal Terhadap Pendapatan Petani Kakao
Hasil penelitian ditemukan terdapat pengaruh positif modal terhadap hasil pendapatan petani 
kakao. Koefisien regresi modal terhadappendapatan petani kakao, dimana nilai $t$ hitung 25,34033 dan nilai $(\mathrm{sig}=0,0000<0,05$

Menurut (Daniel, 2004) modal dapat bergerak. Modal tetap adalah barang-barang yang digunakan dalam proses produksi yang dibutuhkan. Di tunjukkan luas lahan sempit Pengaruh yang lebih besar ada pada kelompok sampel yang cukup luas yaitu sekitar

6. Pengaruh Konsumsi Rumah Tangga, Perubahan Iklim, Monopoli Harga, Perubahan Iklim, Luas Lahan, dan Modal TerhadapPendapatanPetani

Kakao.

Hasil penelitian ditemukan nilai $\mathrm{F}$ hitung 232,0915 dengan nilai $\mathrm{F}$ tabel $(\mathrm{n}-\mathrm{k}-\mathrm{i}=90-6=84)$ jadi $\mathrm{f}$ tabel adalah sebesar 2,32 dapat disimpulkan $\mathrm{F}$ hitung lebih besar dari F tabel $(232,0915>2,32)$ dengan nilai sig 0,000 maka dapat disimpulkan terdapat pengaruh konsumsi Rumah Tangga, perubahan iklim, monopoli harga, luas lahan, modal terhadap hasil pendapatan petani kakao.

Hasil penelitian ini sesuai dengan penelitian (Mawardati, 2015) faktor-faktor yang mempengaruhi pendapatan adalah, produksi, modal, luas lahan tenaga kerja dan harga jual. jual sangat berpengaruh terhadap pendapatan petani. Artinya jumlah pendapatan petani juga dipengaruhi oleh tinggi rendahnya harga jual.

\section{KESIMPULAN}

1. Konsumsi Rumah Tangga berpengaruh terhadap pendapatan petani kakao, pengaruh yang lebih besar terdapat pada kelompok sampel luas lahan sempit yang ditunjukkan oleh nilai koofisiennya sebesar 3,272436 dan nilai signifikan sebesar 0,0002, thitungsebesar 3,961799 > ttabel 1,663 artinya, apabila terjadi perubahan tingkat konsumsi,maka Rumah Tangga petani berlahan sempit lebih sensitif terhadap perubahan pendapatanya

2. Perubahan iklim berpengaruh terhadap pendapatan petani kakao, pengaruh yang lebih besar terdapat pada kelompok sampel luas lahan sempit, yang ditunjukkan oleh nilai koofisiennya sebesar 153741,3 dan nilai signifikan sebesar 0,0321, thitung sebesar 2,204818 
$>$ tabel 1,663 artinya, apabila jumlah hari hujan besar maka petani dengan lahan sempit lebih sensitif terhadap perubahan pendapatannya.

3. Monopoli Harga berpengaruh terhadap pendapatan petani kakao, pengaruh yang lebih besar terdapat pada kelompok sampel luas lahan luas, yang ditunjukkan oleh nilai koofisiennya sebesar 519,0597 dan nilai signifikan sebesar 0,0863, thitungsebesar $1,773693>$ tabel 1,663 artinya apabila terjadi perubahan pada tingkat monopoli harga maka petani dengan lahan luas lebih sensitif terhadap perubahan pendapatannya.

4. Luas lahan tidak berpengaruh terhadap pendapatan petani kakao, pengaruh yang lebih besar terdapat pada kelompok sampel luas lahan luas, yang ditunjukkan oleh nilai koofisiennya sebesar 354,5235 dan nilai signifikan sebesar 0,4054, thitungsebesar $0,844364<$ ttabel 1,663

5. Modal berpengaruh terhadap pendapatan petani kakao, pengaruh yang lebih besar terdapat pada kelompok sampel luas lahan luas, yang ditunjukkan oleh nilai koofisiennya sebesar 0,199645 dan nilai signifikan sebesar 0,0000, thitungsebesar 19,17632 > tabel 1,663. Artinya apabila terjadi perubahan pada tingkat modal maka petani dengan lahan luas lebih sensitif terhadap perubahan pendapatan.

6. Konsumsi Rumah Tangga, perubahan iklim, monopoli harga, luas lahan, dan modal kakao di Nagari Kubang Kecamatan Guguak Kabupaten Lima Puluh kota.

\section{DAFTAR PUSTAKA}

Ansofino, J. Y. (2016). Buku Ajar Ekonometrika. Deepublish.

Daniel, M. (2004). Pengantar Ekonomi Pertanian. Bumi Aksara.

Hamdani, A. P. (2016). Pengaruh Harga Sawit, Jumlah Produksi, Konsumsi, Tabungan Rt, dan Perubahan Iklim Terhadap Pendapatan Rumah Tangga Petani di Kecamatan Kamang Baru Kabupaten Sijunjung Pada Perkebunan Kelapa Sawit. Economica.

Mawardati. (2015). Analisis FaktorFaktor yang Mempengaruhi Pendapatan Usaha Tani Pinang Kecamatan Sawang 
Kabupaten Aceh Utara. Agrisep, 61-65.

Selvia, N. A. (2017). Pengaruh Perubahan Iklim, Harga Jual, Luas Lahan, dan Tingkat Pendidikan Terhadap Pendapatan Petani Karet di Empat Nagari Kambang Kecamatan Lengayang Kabupaten Pesisir Selatan. Economica.

Soekartawi. (2002). Prinsip Dasar Ekonomi Pertanian, Teori dan Dasar Aplikasi. PT. Raja Grapindo Persada.

Yukesma, E. Y. (2017). Pengaruh Harga, Produksi, Iklim, Luas lahan, Pengalaman Kerja Terhadap Pendapatan Petani Karet di Jorong Jambu Lipo Kecamatan Lubuk Tarok Kabupaten Sijunjung. Economica. 